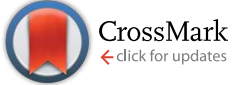

Cite this: J. Mater. Chem. A, 2016, 4, 15896

Received 29th July 2016

Accepted 21st September 2016

DOI: $10.1039 / c 6 t a 06497 c$

www.rsc.org/MaterialsA

\section{Photoinduced degradation of methylammonium lead triiodide perovskite semiconductors $\uparrow$}

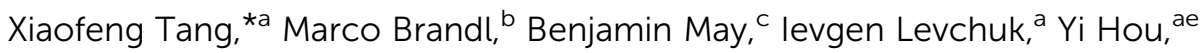 \\ Moses Richter, ${ }^{a}$ Haiwei Chen, ${ }^{a}$ Shi Chen, ${ }^{a}$ Simon Kahmann, ${ }^{a}$ Andres Osvet, ${ }^{a}$ \\ Florian Maier, ${ }^{c}$ Hans-Peter Steinrück, ${ }^{c}$ Rainer Hock, ${ }^{b}$ Gebhard J. Matt ${ }^{\star a}$ \\ and Christoph J. Brabec*ad
}

\begin{abstract}
Photoinduced degradation is a critical obstacle for the real application of novel semiconductors for photovoltaic applications. In this paper, the photoinduced degradation of $\mathrm{CH}_{3} \mathrm{NH}_{3} \mathrm{Pbl}_{3}$ in a vacuum and air (relative humidity $40 \%$ ) is analyzed by ex situ and advanced in situ technologies. Without light illumination, $\mathrm{CH}_{3} \mathrm{NH}_{3} \mathrm{Pbl}_{3}$ films slowly degrade under vacuum and air within 24 hours. However, we find that $\mathrm{CH}_{3} \mathrm{NH}_{3} \mathrm{Pbl}_{3}$ converts to metallic lead $\left(\mathrm{Pb}^{0}\right)$ when exposed to vacuum and light illumination. Further, a series of lead salts (e.g. $\mathrm{PbO}, \mathrm{Pb}(\mathrm{OH})_{2}$ and $\mathrm{PbCO}_{3}$ ) are formed when $\mathrm{CH}_{3} \mathrm{NH}_{3} \mathrm{Pbl}_{3}$ is degraded under environmental conditions, i.e. under the combination of light, oxygen and moisture. Photoinduced degradation is found to be determined by the environmental atmosphere as $\mathrm{CH}_{3} \mathrm{NH}_{3} \mathrm{Pbl}_{3}$ films remain very stable under nitrogen conditions. The results from vacuum conditions underpin that the high volatility of the organic component $\left(\mathrm{CH}_{3} \mathrm{NH}_{3}\right)$ is in conflict with reaching excellent intrinsic stability due to its role in creating ion vacancies. The degradation in air suggests that both oxygen and water contribute to the fast photodecomposition of $\mathrm{CH}_{3} \mathrm{NH}_{3} \mathrm{Pbl}_{3}$ into lead salts rather than water alone. Given these basic yet fundamental understandings, the design of hydrophobic capping layers becomes one prerequisite towards long-term stable perovskite-based devices.
\end{abstract}

\section{Introduction}

Perovskite semiconductors, most notably methylammonium lead triiodide $\left(\mathrm{CH}_{3} \mathrm{NH}_{3} \mathrm{PbI}_{3}\right)$, have manifested themselves as a class of photovoltaic materials offering promising performance in light-energy conversion applications. ${ }^{1}$ Although great success has been achieved by using $\mathrm{CH}_{3} \mathrm{NH}_{3} \mathrm{PbI}_{3}$ as active layers to fabricate solar cells, ${ }^{2} \mathrm{X}$-ray detectors, ${ }^{3}$ light-emitting diodes $\left(\right.$ LEDs) ${ }^{4}$ and lasers, ${ }^{5}$ its long-term stability remains challenging: ${ }^{6,7}$ Efforts to address this problem have already shown critical progress, and perovskite-type solar cells could maintain high power conversion efficiency extending for thousands of

${ }^{a}$ Institute of Materials for Electronics and Energy Technology (I-MEET), Department of Materials Science and Engineering, Friedrich-Alexander-Universität Erlangen-Nürnberg, Martensstrasse 7, 91058 Erlangen, Germany. E-mail: xiaofeng. tang@fau.de; gebhard.matt@fau.de; christoph.brabec@fau.de

${ }^{b}$ Chair for Crystallography and Structural Physics, Friedrich-Alexander-Universität Erlangen-Nürnberg, Staudtstrasse 3, 91058 Erlangen, Germany

${ }^{c}$ Chair of Physical Chemistry II, Friedrich-Alexander-Universität Erlangen-Nürnberg, Egerlandstrasse 3, 91058 Erlangen, Germany

${ }^{d}$ Bavarian Center for Applied Energy Research (ZAE Bayern), Haberstrasse 2a, 91058 Erlangen, Germany

${ }^{e}$ Erlangen Graduate School in Advanced Optical Technologies (SAOT), Paul-GordanStrasse 6, 91052 Erlangen, Germany

$\dagger$ Electronic supplementary information (ESI) available. See DOI: $10.1039 / \mathrm{c} 6 \mathrm{ta} 06497 \mathrm{c}$ hours when well packaged. ${ }^{8}$ Despite this progress, the environmental instability of the $\mathrm{CH}_{3} \mathrm{NH}_{3} \mathrm{PbI}_{3}$ semiconductor still remains a major obstacle. A better understanding of the degradation mechanism is therefore critical to further guide the development of perovskite-based devices which are suitable for future commercialization.

The stability of $\mathrm{CH}_{3} \mathrm{NH}_{3} \mathrm{PbI}_{3}$ has been systematically investigated and several factors, like humidity, ${ }^{9}$ heat, ${ }^{10}$ electric bias, ${ }^{\mathbf{1 1}}$ etc., were identified as the possible reasons for degradation. For instance, the degradation of $\mathrm{CH}_{3} \mathrm{NH}_{3} \mathrm{PbI}_{3}$ was monitored as a function of humidity, and the degradation rate was found to be strongly dependent on humidity. ${ }^{9}$ Heat is another factor affecting stability due to the highly volatile nature and thermal instability of $\mathrm{CH}_{3} \mathrm{NH}_{3} \mathrm{I}^{10}$ In addition, by applying an electric field to $\mathrm{CH}_{3} \mathrm{NH}_{3} \mathrm{PbI}_{3}$, organic cations $\left(\mathrm{CH}_{3} \mathrm{NH}_{3}{ }^{+}\right)$can drift and form unstable $\mathrm{PbI}_{6}{ }^{4-}$ octahedral complexes which further decompose into $\mathrm{PbI}_{2}$ and excess iodide. ${ }^{11}$

With regard to photovoltaic materials, the relevant light stability is a crucial criterion determining the quality of the package against water and oxygen. Although the transformation of $\mathrm{CH}_{3} \mathrm{NH}_{3} \mathrm{PbI}_{3}$ films into $\mathrm{PbI}_{2}$ and other reaction products has been reported as mentioned above, understanding the mechanism of photoinduced degradation of $\mathrm{CH}_{3} \mathrm{NH}_{3} \mathrm{PbI}_{3}$ is still in its infancy. Furthermore, precise knowledge of the influence of the atmosphere on the photoinduced degradation may trigger the 
development of new device architectures with enhanced stability.

In this manuscript, we provide a detailed description of the optical, chemical and structural modifications of $\mathrm{CH}_{3} \mathrm{NH}_{3} \mathrm{PbI}_{3}$ films exposed to different atmospheres in the dark and under white light illumination. In a vacuum or under air, $\mathrm{CH}_{3} \mathrm{NH}_{3} \mathrm{PbI}_{3}$ films tend to be stable in the dark for 24 hours. Uncustomary degradation products like metallic lead $\left(\mathrm{Pb}^{0}\right)$ or lead salts $\left(\mathrm{PbO}, \mathrm{Pb}(\mathrm{OH})_{2}\right.$ and $\left.\mathrm{PbCO}_{3}\right)$ are found when films were subjected to illumination. On the basis of ex situ analysis and in situ X-ray diffraction (XRD) measurements, we propose various degradation mechanisms as a function of environmental conditions. In a vacuum, the loss of the highly volatile $\mathrm{CH}_{3} \mathrm{NH}_{3} \mathrm{I}$ triggers the creation of iodine vacancies and further reduces $\mathrm{Pb}^{2+}$ into $\mathrm{Pb}^{0}$. Photoinduced degradation in air is shown to cause a fast photodecomposition of $\mathrm{CH}_{3} \mathrm{NH}_{3} \mathrm{PbI}_{3}$ into lead salts. The detailed understanding of the degradation mechanism and the factors determining degradation kinetics is expected to contribute towards the development of long-term stable perovskite semiconductors. The in situ method under controlled environmental conditions described here shows its potential in tracking the kinetics of the structural and/or chemical changes. The gained in-depth insights are beyond a simple investigation of the final products.

\section{Experimental section}

\section{Sample preparation}

Quartz substrates were rinsed with toluene, acetone and isopropyl alcohol and then blown dry with nitrogen flow. $\mathrm{PbI}_{2}$ and $\mathrm{CH}_{3} \mathrm{NH}_{3} \mathrm{I}$ were purchased from Sigma-Aldrich and Lumtec and mixed in a molar ratio of $1: 1$ at a concentration of $40 \%$ and were stirred at $60{ }^{\circ} \mathrm{C}$ in a mixture of DMF and DMSO $(7: 3 \mathrm{v} / \mathrm{v})$. The as-prepared perovskite precursor solution was filtered using a $0.45 \mu \mathrm{m}$ PTFE syringe filter and coated onto a clean substrate at a speed of 3000 r.p.m for 35 s. During the last $6 \mathrm{~s}$ of the spinning process, the substrate was treated with chlorobenzene drop-casting. The substrate was dried on a hot plate at $100{ }^{\circ} \mathrm{C}$ for $10 \mathrm{~min}$. All samples and solutions were prepared in an inert nitrogen atmosphere.

\section{Ageing}

All the aging experiments were conducted in a self-made cryostat with a temperature controller. A white LED (lamp spectrum in Fig. S1 $\dagger$ ) was used for illumination purposes and the LED intensity was adjusted in a way that the generated photocurrent matched the one under a solar simulator. For testing in nitrogen, pure nitrogen was passed through the cryostat keeping the temperature constant at $350 \mathrm{~K}$. To study the degradation in a vacuum, we subjected the samples continuously to a temperature of $350 \mathrm{~K}$ and under $10^{-6} \mathrm{mbar}$. For aging in air, the samples were left in the cryostat with a gas valve opening, at a constant temperature of $350 \mathrm{~K}$ and a relative humidity of $40 \%$. To investigate the influence of the oxygen atmosphere, $\mathrm{N}_{2}$ gas or $\mathrm{N}_{2}$ saturated with $\mathrm{H}_{2} \mathrm{O}$ was passed during the degradation.

\section{Characterization}

The absorbance spectra were obtained by using a UV-VIS-NIR spectrometer (Lambda 950, from Perkin). The photoluminescence spectra were recorded using a home-built setup. The samples were excited with a $450 \mathrm{~nm}$ diode laser (Oxxius)

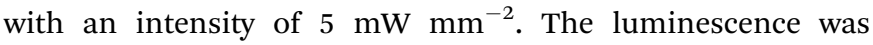
collected in a back-scattering geometry, dispersed by an iHR320 monochromator (Horiba Jobin-Yvon), and recorded with a Peltier-cooled Si CCd (Synapse, Horiba Jobin-Yvon). The FTPS measurements were performed with a Bruker Vertex 70 FTIR spectrometer operated in the fast-scan mode, equipped with a tungsten lamp and a quartz beam-splitter. A low noise current amplifier (DLPCA-200) is used to amplify the photocurrent produced upon illumination of the photovoltaic devices with light modulated by the FTIR. The output voltage of the current amplifier is fed back to the external detector port of the FTIR, in order to be able to use the FTIR's software to collect the photocurrent spectrum. In situ X-ray powder diffraction measurements were carried out using a transmission geometry (Debye-Scherrer) diffraction setup. As a source of radiation, a rotating $\mathrm{Cu}$ anode with double focusing Goebel mirrors was used. The diffraction rings were recorded by a CCD area detector. For this type of measurement, $\mathrm{CH}_{3} \mathrm{NH}_{3} \mathrm{PbI}_{3}$ was applied to X-ray transparent polyimide foil (KAPTON®) and fixed inside a heating chamber with a nitrogen or air atmosphere or vacuum. For the light stability measurements the sample was illuminated from the outside of the chamber through a Kapton window by using a LED. During the measurement, the sample was kept at a constant temperature of $350 \mathrm{~K}$. Each sample was measured for 24 hours. During this time, diffractograms were measured continuously with 10 minutes illumination time each. The X-ray photoelectron spectra were collected using an $\mathrm{Al} \mathrm{K} \alpha$ X-ray source ( $h \nu=1486.6 \mathrm{eV}, U=12.5 \mathrm{kV}, I=20 \mathrm{~mA}$ ), and a VG Scienta R3000 analyser (PE $200 \mathrm{eV}$ for wide and $100 \mathrm{eV}$ for region scans) at normal emission. All samples were measured without further processing. The samples were mounted onto a standard sample holder with double-sided adhesive copper tape. Silver conductive paint was applied as a thin line on the edge of the material, and as a track to the sample holder, to ground the perovskite. Spectra were charge corrected such that the $\mathrm{I}_{3 / 2}$ peak was at $619.5 \mathrm{eV}$.

\section{Results and discussion}

Perovskite solar cell devices frequently use metal oxides like $\mathrm{TiO}_{2}, \mathrm{NiO}_{x}$ and $\mathrm{ZnO}$ as electron transport layers and poly(3,4-ethylenedioxythiophene):polystyrenesulfonate (PEDOT:PSS) and $\quad 2,2^{\prime}, 7,7^{\prime}$-tetrakis[ $N, N$-di(4-methoxyphenyl)amino]-9, $9^{\prime}$-spirobifluorene (Spiro-MeOTAD) as hole transport layers. ${ }^{\mathbf{1 2 - 1 4}}$ However, metal oxides are a class of reactive or even catalytic semiconductors and are rather sensitive to light (especially to UV). ${ }^{15,16}$ Further, PEDOT:PSS as well as Spiro-MeOTAD are prone to photooxidation by themselves. ${ }^{17,18}$ As a result, it is quite challenging to discriminate the intrinsic light instability of perovskite semiconductors from the degradation mechanism caused by the interface or transport layers. Therefore, in this work, $\mathrm{CH}_{3} \mathrm{NH}_{3} \mathrm{PbI}_{3}$ thin films without any interface layer are studied. As 
light illumination will further cause local heating, we discriminate the photoinduced thermal stress by keeping the temperature of all samples at $350 \mathrm{~K}$.

$\mathrm{CH}_{3} \mathrm{NH}_{3} \mathrm{PbI}_{3}$ films were subjected to $350 \mathrm{~K}$ under pure nitrogen, vacuum $\left(10^{-6} \mathrm{mbar}\right)$ or air (with a relative humidity of $40 \%$ ) without (air/dark) or with illumination (air/light) for 24 hours. As shown in Fig. 1, after 24 hours, $\mathrm{CH}_{3} \mathrm{NH}_{3} \mathrm{PbI}_{3}$ films in a $\mathrm{N}_{2}$ atmosphere show no obvious color conversion, independent of the illumination conditions. This is very different compared to the samples kept under vacuum or in air. In a vacuum and under illumination (vacuum/light), the color of the $\mathrm{CH}_{3} \mathrm{NH}_{3} \mathrm{PbI}_{3}$ film turns from dark brown to gray, while in air, the film changes were dramatic from dark brown to transparent. The change of the color means that significant transformations occurred after exposing $\mathrm{CH}_{3} \mathrm{NH}_{3} \mathrm{PbI}_{3}$ to light for 24 hours in a vacuum or air. This is further underlined by optical measurements (Fig. 2). The bulk optical absorption of samples degraded in $\mathrm{N}_{2}$ /dark or $\mathrm{N}_{2}$ /light (Fig. 2a) has a slight decrease as compared to that of the fresh sample. The same trend holds for the PL emission (Fig. 2d). The sample under vacuum and in the dark has a more significant drop in absorbance and an advanced drop in PL. In strong contrast, samples under vacuum and illumination are completely decomposed, and no absorption and PL features from perovskite remain (Fig. 2b and e). Similar results were observed for the samples subjected to air/light. Overall, the optical measurements provide clear evidence that $\mathrm{CH}_{3} \mathrm{NH}_{3} \mathrm{PbI}_{3}$ degradation under vacuum or air is significantly accelerated by light.

To better rationalize the impact of light on the degradation of $\mathrm{CH}_{3} \mathrm{NH}_{3} \mathrm{PbI}_{3}$, the composition of the degraded $\mathrm{CH}_{3} \mathrm{NH}_{3} \mathrm{PbI}_{3}$ films was further investigated by $\mathrm{X}$-ray diffraction (XRD) and X-ray photoelectron spectra (XPS). Not surprisingly, Fig. 3a shows negligible changes in the diffractograms of samples degraded in $\mathrm{N}_{2}$ even under illumination. Light does not cause obvious optical and structural changes in $\mathrm{CH}_{3} \mathrm{NH}_{3} \mathrm{PbI}_{3}$ under a nitrogen atmosphere. Degradation in a vacuum/dark leads to one additional peak at $2 \theta=12.7^{\circ}$ corresponding to the presence of $\mathrm{PbI}_{2}$ (001). ${ }^{19,20}$ Degradation in air/dark results in no new peaks as compared to the fresh sample. Significant changes are found in $\mathrm{CH}_{3} \mathrm{NH}_{3} \mathrm{PbI}_{3}$ degraded in a vacuum/light and air/light. Degradation in a vacuum/light (Fig. $3 \mathrm{~b}$ ) results in three typical diffraction peaks at the $2 \theta$ values of $31.4^{\circ}, 36.3^{\circ}, 53.9^{\circ}, 64.3^{\circ}$ and $67.5^{\circ}$ of the (111), (002), (022), (113) and (222) crystal planes of metallic lead $\left(\mathrm{Pb}^{0}\right) \cdot{ }^{21}$ The transformation into metallic $\mathrm{Pb}^{0}$

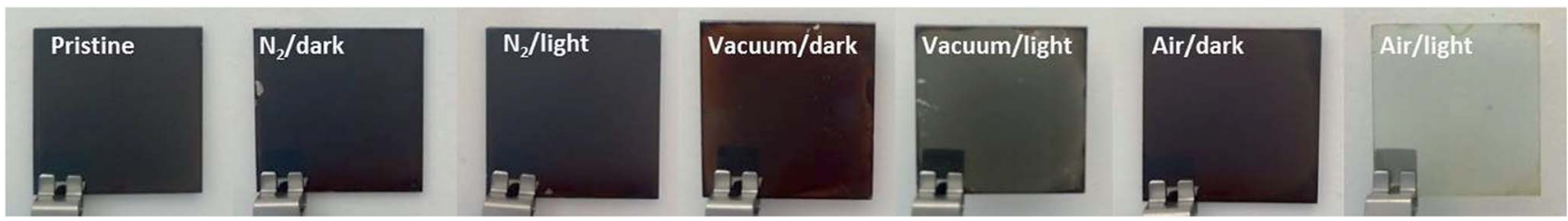

Fig. 1 Photographs of $\mathrm{CH}_{3} \mathrm{NH}_{3} \mathrm{Pbl}_{3}$ films exposed in several atmospheres for 24 hours.
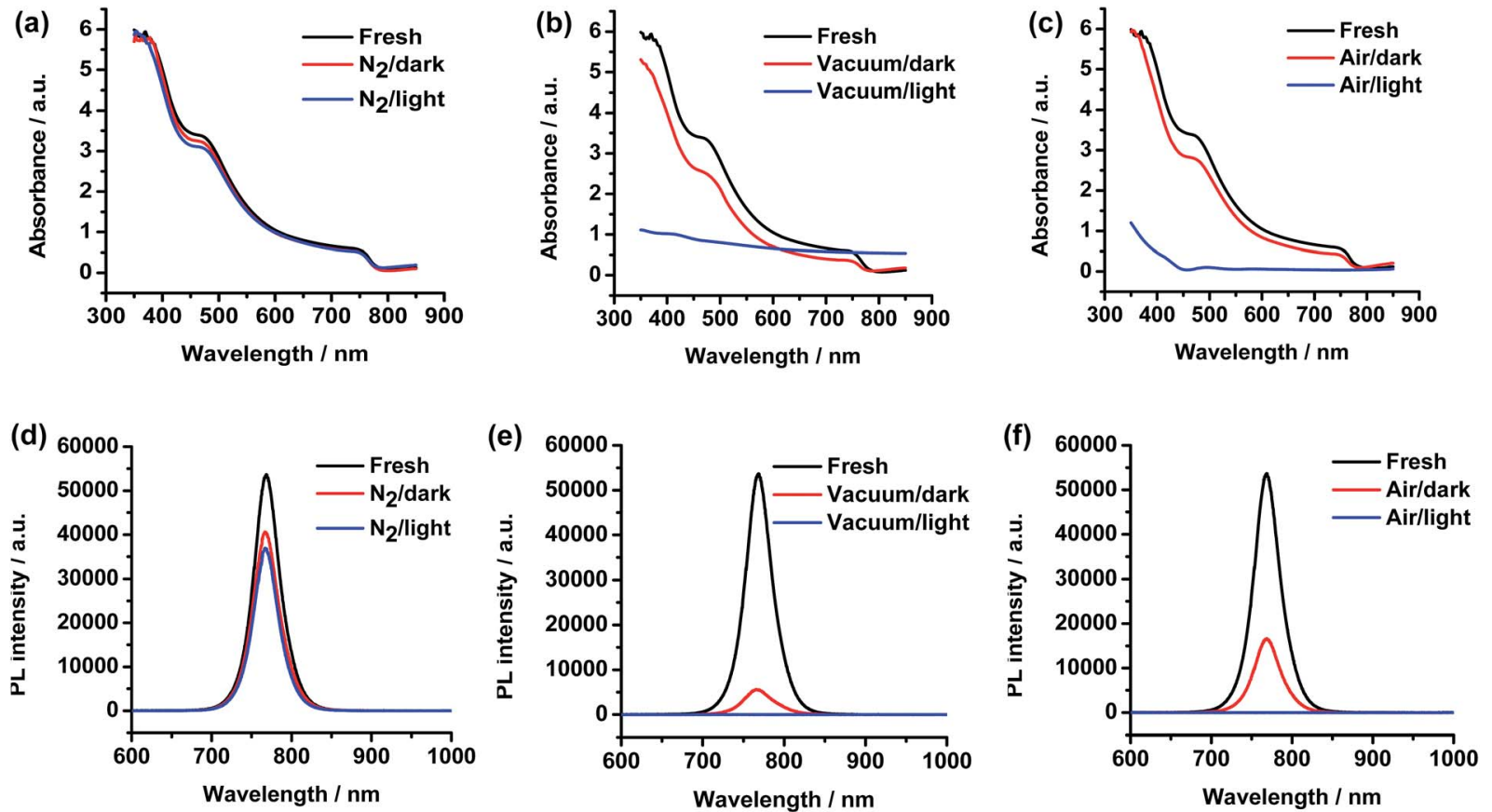

Fig. 2 Absorbance spectra of $\mathrm{CH}_{3} \mathrm{NH}_{3} \mathrm{Pbl}_{3}$ films degraded for 24 hours in $\mathrm{N}_{2}$ (a), vacuum (b) and air (c), and corresponding steady-state photoluminescence (d), (e) and (f). 

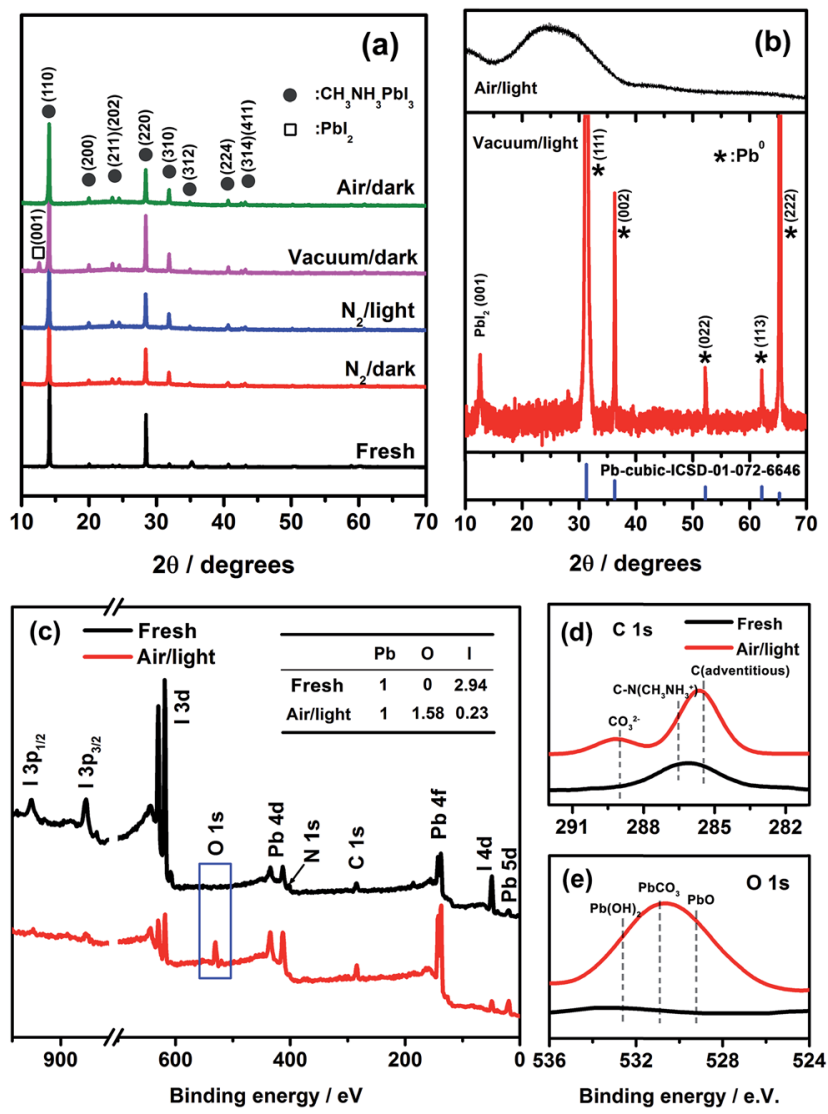

Fig. 3 (a and b) X-ray diffractograms of $\mathrm{CH}_{3} \mathrm{NH}_{3} \mathrm{Pbl}_{3}$ films degraded in different atmospheres for $24 \mathrm{~h}$. The XRD diffraction result from vacuum/light shows agreement with diffraction data for metallic lead $\left(\mathrm{Pb}^{0}\right)$ taken from the ICSD database (card no. 01-072-6646). XPS of fresh $\mathrm{CH}_{3} \mathrm{NH}_{3} \mathrm{Pbl}_{3}$ and $\mathrm{CH}_{3} \mathrm{NH}_{3} \mathrm{Pbl}_{3}$ degraded in air for $24 \mathrm{~h}$ at $350 \mathrm{~K}$ : survey spectrum (c), (inset: the ratio of $\mathrm{Pb}: \mathrm{O}:$ I of fresh and degraded $\mathrm{CH}_{3} \mathrm{NH}_{3} \mathrm{Pbl}_{3}$ ), $\mathrm{C}$ 1s (d) and $\mathrm{O}$ 1s (e) binding energy regions.

agrees well with the XPS results (Fig. S2†). The atomic ratio of $\mathrm{I} / \mathrm{Pb}$, as calculated from the spectra, decreases from $2.94: 1$ (which is in very good agreement with the nominal stoichiometry of $3: 1$ for $\mathrm{CH}_{3} \mathrm{NH}_{3} \mathrm{PbI}_{3}$ ) to $0.63: 1$ after degradation under vacuum/light for 24 hours. The fresh sample shows two strong peaks at a binding energy of 143.5 and $138.6 \mathrm{eV}$ representing the $\mathrm{Pb} 4 \mathrm{f}$ levels of $\mathrm{a}^{2+}$ component. ${ }^{22}$ For the perovskite degraded in a vacuum/light, two shoulder peaks at 141.7 and $136.7 \mathrm{eV}$ (Fig. S2b $\dagger$ ) clearly reveal the additional presence of metallic lead. ${ }^{23}$ Both XRD and XPS thus provide evidence for the transformation of $\mathrm{CH}_{3} \mathrm{NH}_{3} \mathrm{PbI}_{3}$ into $\mathrm{Pb}^{0}$ during the photoinduced degradation in a vacuum. Next, we discuss the sample degraded in air/light. According to the XRD measurement in Fig. 3b, the $\mathrm{CH}_{3} \mathrm{NH}_{3} \mathrm{PbI}_{3}$ structure is completely destroyed and no peak corresponding to a crystal structure is observed. This means that polycrystalline $\mathrm{CH}_{3} \mathrm{NH}_{3} \mathrm{PbI}_{3}$ completely degrades into products with amorphous nature. The composition and binding state of the as-formed amorphous film were further investigated by XPS. The survey spectra of fresh $\mathrm{CH}_{3} \mathrm{NH}_{3} \mathrm{PbI}_{3}$ and $\mathrm{CH}_{3} \mathrm{NH}_{3} \mathrm{PbI}_{3}$ degraded in air/light are shown in Fig. 3c. The calculated atomic ratio of $\mathrm{O} / \mathrm{Pb}$ increases from $0: 1$ to $1.6: 1$, evidencing that oxygen-containing compounds were formed during degradation in air/light. The chemical structure of the degraded sample was further analyzed with respect to elements $\mathrm{C}, \mathrm{N}$ and $\mathrm{O}$. The ammonium nitrogen signal at $402.5 \mathrm{eV}$ in the $\mathrm{N}$ 1s spectrum (Fig. S2c $\dagger$ ) is absent for the air/light sample, which means that $\mathrm{CH}_{3} \mathrm{NH}_{3} \mathrm{PbI}_{3}$ films were completely decomposed. Moreover, the $\mathrm{C} 1 \mathrm{~s}$ spectrum in Fig. $3 \mathrm{~d}$ also changes. The fresh sample contains a broad peak at $286.5 \mathrm{eV}$, which originates mainly from the $\mathrm{C}-\mathrm{N}^{+}$bond from $\mathrm{CH}_{3} \mathrm{NH}_{3}{ }^{+}$, and some contribution of adventitious carbon (around $285.7 \mathrm{eV}$ ), which cannot be resolved as a separate signal. ${ }^{10}$ After subjecting $\mathrm{CH}_{3} \mathrm{NH}_{3} \mathrm{PbI}_{3}$ to air/light, the $\mathrm{C}-\mathrm{N}^{+}$related peak vanishes and the adventitious carbon increases in the $\mathrm{C}$ 1s spectra (Fig. 3d). This is in excellent agreement with the absence of any nitrogen-related peak in the $\mathrm{N}$ 1s spectrum (Fig. S2c $\dagger$ ). In addition, a novel peak at the binding energy of $289.1 \mathrm{eV}$ arises, which corresponds to carbonate species. ${ }^{24}$ This peak thus suggests the formation of $\mathrm{PbCO}_{3}$ during the degradation in air/light. Furthermore, the $\mathrm{O}$ 1s spectrum (Fig. 3e) of the fresh $\mathrm{CH}_{3} \mathrm{NH}_{3} \mathrm{PbI}_{3}$ film shows no oxygen signal, while after degradation in air/light, a broad peak at a binding energy of $531.0 \mathrm{eV}$ is observed. The broad $\mathrm{O} 1 \mathrm{~s}$ signal can be consistently decomposed into three different oxygen species, which, according to the literature, can be assigned to $\mathrm{Pb}(\mathrm{OH})_{2}$ at $532.6 \mathrm{eV}, \mathrm{PbCO}_{3}$ at $531.1 \mathrm{eV}$ and $\mathrm{PbO}$ at $529.3 \mathrm{eV}^{24-27}$ The finding of $\mathrm{PbCO}_{3}$ in the $\mathrm{O} 1 \mathrm{~s}$ spectrum is in excellent agreement with the carbonate peak in the $\mathrm{C} 1 \mathrm{~s}$ spectrum. In summary, we conclude that upon photoinduced degradation in air, $\mathrm{CH}_{3} \mathrm{NH}_{3} \mathrm{PbI}_{3}$ decomposes into lead salts (e.g. $\mathrm{PbO}, \mathrm{Pb}(\mathrm{OH})_{2}$ and $\mathrm{PbCO}_{3}$ ). It is noted that the XPS can hardly distinguish different complex combinations, such as $\mathrm{Pb}_{3}\left(\mathrm{CO}_{3}\right)_{2}(\mathrm{OH})_{2} \cdot{ }^{28}$ Therefore the proposed compounds are selected as the simplest representative.

Besides the optical and chemical changes, one of the most device-relevant material parameters is the defect concentration. To investigate the defect concentration of $\mathrm{CH}_{3} \mathrm{NH}_{3} \mathrm{PbI}_{3}$ thin films, we directly fabricated $\mathrm{CH}_{3} \mathrm{NH}_{3} \mathrm{PbI}_{3}$ films on top of FTO interdigitated electrodes with an electrode distance of $20 \mu \mathrm{m}$ (Fig. S3 $\dagger$ ) and characterized them by Fourier Transform Photocurrent Spectroscopy (FTPS). Absorption of FTO does not induce free charge carriers and therefore has no contribution to the photocurrent collected during the FTPS measurements. ${ }^{29}$ As shown in Fig. 4, the fresh $\mathrm{CH}_{3} \mathrm{NH}_{3} \mathrm{PbI}_{3}$ has a sharp onset at $\approx 1.6 \mathrm{eV}$ and a spectrally well resolved photocurrent. Moreover, as seen in the Tauc plot $^{30}$ (Fig. $\mathrm{S} 4 \dagger$ ), no well pronounced subbandgap states (e.g. Urbach tail) could be detected in the fresh sample. ${ }^{29}$ Compared to fresh $\mathrm{CH}_{3} \mathrm{NH}_{3} \mathrm{PbI}_{3}$, the FTPS spectrum shows no difference after degradation in nitrogen for 24 hours (Fig. 4a). This means that under nitrogen, 24 hours of light illumination neither causes chemical or structural transformation nor changes in the defect density. After degradation in a vacuum without light illumination for 24 hours, the defect density of $\mathrm{CH}_{3} \mathrm{NH}_{3} \mathrm{PbI}_{3}$ increases, which results in a defect absorption down to $1.2 \mathrm{eV}$ (Fig. $4 \mathrm{~b}$ and $\mathrm{S} 4 \mathrm{~b} \dagger$ ). Because $\mathrm{CH}_{3} \mathrm{NH}_{3} \mathrm{PbI}_{3}$ degraded into metallic lead or lead salts under vacuum/light or air/light after 24 hours, there is no detectable FTPS signal. As a result, we choose to analyze the FTPS signals of $\mathrm{CH}_{3} \mathrm{NH}_{3} \mathrm{PbI}_{3}$ under vacuum/light or air/light after 1 hour illumination to show the influence of degradation on the defect 

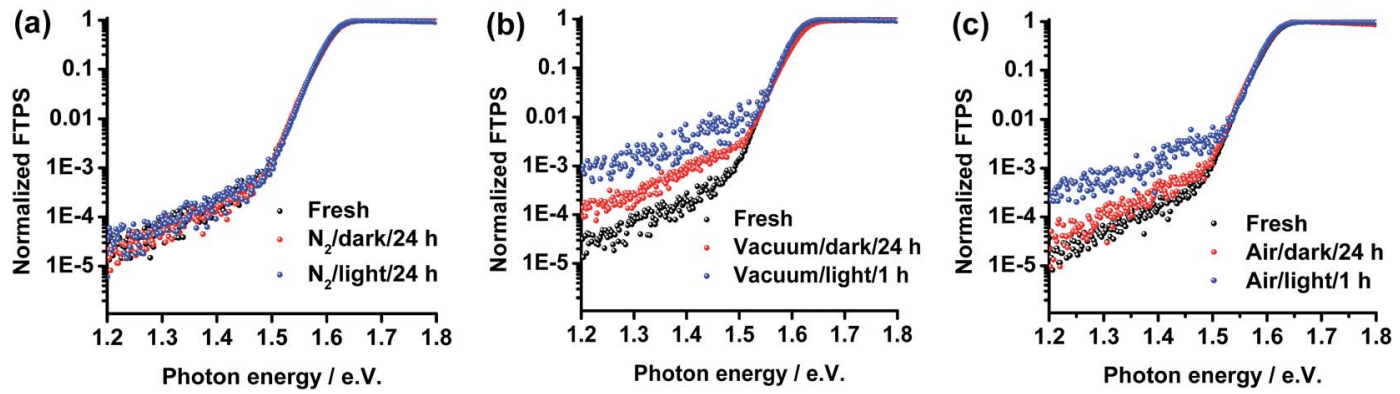

Fig. 4 Spectrally resolved photoconductivity of $\mathrm{CH}_{3} \mathrm{NH}_{3} \mathrm{Pbl}_{3}$ films after the degradation in different atmospheres for various time.

density. In this case, $\mathrm{CH}_{3} \mathrm{NH}_{3} \mathrm{PbI}_{3}$ is partially degraded and well pronounced tail states are formed (Fig. S4b and c $\dagger$ ). As shown in Fig. 4b, within a shorter degradation time of only 1 hour, a higher density of defects is observed after degradation under vacuum/light. This is explained by the faster degradation of $\mathrm{CH}_{3} \mathrm{NH}_{3} \mathrm{PbI}_{3}$ and by the formation of $\mathrm{Pb}^{0}$ which can act as the defect center for carriers. The Tauc plot analysis directly corresponds to the FTPS signal (Fig. S4b $\dagger$ ). We further tested FTPS of $\mathrm{CH}_{3} \mathrm{NH}_{3} \mathrm{PbI}_{3}$ after degradation in air. Without light illumination, we see a negligible increase in the sub-bandgap defect density. Under light illumination for 1 hour, photoinduced degradation also leads to a dramatic increase in the density of sub-gap defects. The sharp adsorption edge is no longer obtained in the region between 1.2 and $1.6 \mathrm{eV}$ after 1 hour in air/light, owing to the substantial chemical decomposition of $\mathrm{CH}_{3} \mathrm{NH}_{3} \mathrm{PbI}_{3}$. These studies suggest that light not only significantly accelerates degradation, but also can trigger different degradation mechanisms as a function of environmental conditions causing the intense formation of subbandgap defects.

Although ex situ UV-vis, PL, XRD, XPS and FTPS measurements provide detailed information on the degradation mechanism, they provide no insight into the degradation kinetics. For this purpose, in situ X-ray diffraction (XRD) experiments were carried out in order to trace the real-time variation of photoinduced degradation in a vacuum and air. Fig. 5 shows the XRD evolution of $\mathrm{CH}_{3} \mathrm{NH}_{3} \mathrm{PbI}_{3}$ in a vacuum/dark (Fig. 5a) vs. vacuum/light (Fig. 5b) for 24 hours. Under vacuum/dark conditions, the intensity of the $\mathrm{CH}_{3} \mathrm{NH}_{3} \mathrm{PbI}_{3}$-related peaks reduces during 24 hours and the peak at $2 \theta=39.5^{\circ}$ of $\mathrm{PbI}_{2}$ $(110)^{19,20}$ is already distinguished after 12 hours. This confirms that the loss of $\mathrm{CH}_{3} \mathrm{NH}_{3} \mathrm{PbI}_{3}$ occurs in parallel with the formation of $\mathrm{PbI}_{2}$. The degradation under vacuum/light is apparently much faster. The diffraction peaks related to $\mathrm{CH}_{3} \mathrm{NH}_{3} \mathrm{PbI}_{3}$ diminish from the beginning of degradation and vanish after only 6 hours. Moreover, $\mathrm{Pb}^{0}\left(2 \theta=31.4^{\circ} \text { and } 36.3^{\circ}\right)^{21}$ and $\mathrm{PbI}_{2}$ $\left(2 \theta=39.5^{\circ}\right)^{19,20}$ peaks are found from the beginning of degradation, and subsequently, the intensity of these peaks increases rapidly. Most interestingly, the formation of $\mathrm{Pb}^{0}$ and $\mathrm{PbI}_{2}$ shows the same kinetics as the degradation of $\mathrm{CH}_{3} \mathrm{NH}_{3} \mathrm{PbI}_{3}$, and this observation indicates that the formation of $\mathrm{Pb}^{0}$ and $\mathrm{PbI}_{2}$ is directly correlated with the decomposition of $\mathrm{CH}_{3} \mathrm{NH}_{3} \mathrm{PbI}_{3}$. It was reported that the fast photoinduced degradation in a vacuum is mainly not via a chemical reaction but rather through the creation of vacancies. ${ }^{31}$ Commonly, through photolysis, $\mathrm{PbI}_{2}$ in a vacuum decomposes into $\mathrm{Pb}^{0}$ and $\mathrm{I}_{2}$, and this process has been the subject of a number of studies, employing a variety of techniques. ${ }^{32-35} \mathrm{~A}$ reaction route was proposed and is summarized in Fig. S5. $\dagger$ After the creation of electron-hole pairs with a diffusion length sufficient to reach the free surface, holes are trapped by surface cation vacancies, $\mathrm{Pb}^{2+}$, and further react with the adjacent iodide ions $\left(\mathrm{I}^{-}\right)$to form molecular iodine. Moreover, an excess of anion vacancies trap photogenerated electrons, which will react with the adjacent $\mathrm{Pb}^{2+}$ to create $\mathrm{Pb}^{0}$. This photodecomposition process is heavily dependent on the defect density. ${ }^{33}$ With respect to $\mathrm{CH}_{3} \mathrm{NH}_{3} \mathrm{PbI}_{3}$, because it has a crystal structure that can be regarded as a sum of two interlaced sublattices, an octahedron of anions $\left(\mathrm{PbI}_{6}\right)^{4-}$ and an organic cation $\mathrm{CH}_{3} \mathrm{NH}_{3}{ }^{+}$, the high volatility of series formations of $\mathrm{CH}_{3} \mathrm{NH}_{3}{ }^{+}\left(\mathrm{CH}_{3} \mathrm{NH}_{3} \mathrm{I}, \mathrm{CH}_{3} \mathrm{NH}_{3}{ }^{+}\right.$, or the degradation product, $\mathrm{CH}_{3} \mathrm{NH}_{2}$ ) has been demonstrated to significantly affect the photodecomposition in a vacuum. It has been reported that the decomposition of $\mathrm{CH}_{3} \mathrm{NH}_{3} \mathrm{PbI}_{3}$ in a vacuum occurs through the statistical formation of non-ionic molecular defects $\left(\mathrm{CH}_{3} \mathrm{NH}_{3} \mathrm{I}\right)$ rather than ionic ones. ${ }^{30}$ This means that the loss of the $\mathrm{CH}_{3} \mathrm{NH}_{3}{ }^{+}$cation is bound to the capture of iodide from the octahedron lattice $\left(\mathrm{PbI}_{6}\right)^{4-}$, thus creating iodine vacancies in the $\mathrm{CH}_{3} \mathrm{NH}_{3} \mathrm{PbI}_{3}$ films. We claim that the created iodine vacancy from the $\mathrm{CH}_{3} \mathrm{NH}_{3} \mathrm{I}$ loss is the initial step of the photoinduced degradation of $\mathrm{CH}_{3} \mathrm{NH}_{3} \mathrm{PbI}_{3}$ in a vacuum. This photodecomposition follows a similar route to the photolysis of $\mathrm{PbI}_{2}$. The potential reaction scheme is shown below:

$$
\begin{gathered}
\mathrm{CH}_{3} \mathrm{NH}_{3} \mathrm{PbI}_{3} \stackrel{\text { vacuum }}{\longrightarrow} \mathrm{CH}_{3} \mathrm{NH}_{2(\mathrm{~g})}+\mathrm{HI}_{(\mathrm{g})}+\mathrm{PbI}_{2}+\mathrm{V}_{\mathrm{I}}^{-} \\
\mathrm{e}+\mathrm{V}_{\mathrm{I}}^{-} \stackrel{\text { trapped }}{\longrightarrow} \mathrm{e}\left(\mathrm{V}_{\mathrm{I}}^{-}\right) \\
\mathrm{e}\left(\mathrm{V}_{\mathrm{I}}^{-}\right)+\mathrm{Pb}^{2+} \rightarrow \mathrm{Pb}^{+}+2 \mathrm{I}^{-}+\mathrm{V}_{\mathrm{Pb}}^{2+} \\
2 \mathrm{~Pb}^{+} \rightarrow \mathrm{Pb}^{0}+\mathrm{Pb}^{2+} \\
\mathrm{h}+\mathrm{V}_{\mathrm{Pb}}^{2+} \stackrel{\text { trapped }}{\longrightarrow} \mathrm{h}\left(\mathrm{V}_{\mathrm{Pb}^{2+}}\right)
\end{gathered}
$$



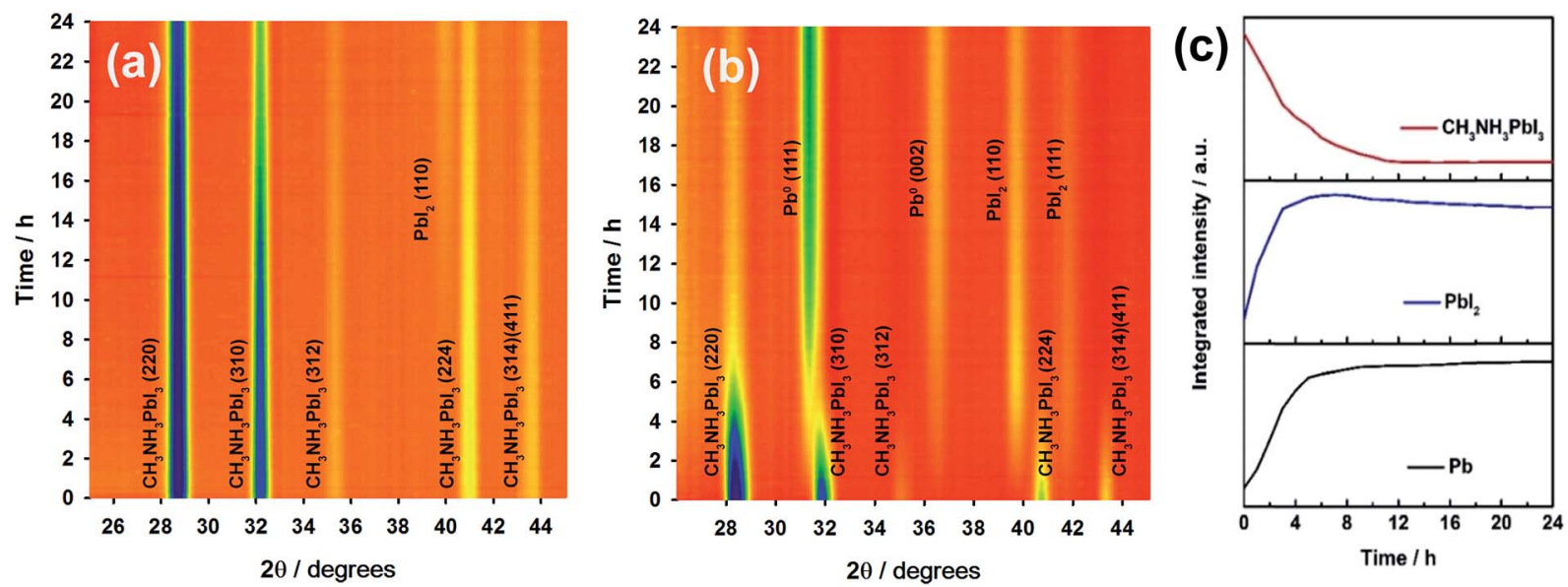

Fig. 5 (a) In situ XRD of $\mathrm{CH}_{3} \mathrm{NH}_{3} \mathrm{Pbl}_{3}$ films at $350 \mathrm{~K}$ under vacuum/dark and (b) vacuum/light. (c) Integrated intensity calculated from in situ XRD patterns of $\mathrm{CH}_{3} \mathrm{NH}_{3} \mathrm{Pbl}$ films at $350 \mathrm{~K}$ under vacuum/light. Selected peaks assigned to $\mathrm{CH}_{3} \mathrm{NH}_{3} \mathrm{Pbl}_{3}\left(2 \theta=28.5^{\circ}\right), \mathrm{Pbl}_{2}\left(2 \theta=39.5^{\circ}\right)$ and $\mathrm{Pb}^{\circ}$ $\left(2 \theta=36.3^{\circ}\right)$

$$
\begin{aligned}
& 2 \mathrm{~h}\left(\mathrm{~V}_{\mathrm{Pb}}{ }^{2+}\right)+2 \mathrm{I}^{-} \rightarrow \mathrm{I}_{2} \\
& 2 \mathrm{CH}_{3} \mathrm{NH}_{3} \mathrm{PbI}_{3} \underset{\text { light }}{\stackrel{\text { vacuum }}{\longrightarrow}} 2 \mathrm{CH}_{3} \mathrm{NH}_{2(\mathrm{~g})}+2 \mathrm{HI}_{(\mathrm{g})}+\mathrm{PbI}_{2}+\mathrm{Pb}+\mathrm{I}_{2(\mathrm{~g})} \\
& \mathrm{PbI}_{2} \underset{\text { light }}{\stackrel{\text { vacuum }}{\longrightarrow}} \mathrm{Pb}+\mathrm{I}_{2(\mathrm{~g})}
\end{aligned}
$$

During degradation in a vacuum, highly volatile $\mathrm{CH}_{3} \mathrm{NH}_{3} \mathrm{I}$ is formed together with iodine vacancies $\left(\mathrm{V}_{\mathrm{I}}^{-}\right)$which can trap photogenerated electrons. The trapped electron triggers the reduction of adjacent $\mathrm{Pb}^{2+}$ to $\mathrm{Pb}^{+}$, and due to the thermodynamic instability of $\mathrm{Pb}^{+}$, two $\mathrm{Pb}^{+}$ions further react to form $\mathrm{Pb}^{0}$ and $\mathrm{Pb}^{2+}$. The formation of $\mathrm{Pb}^{0}$ leads to lead vacancies in the $\mathrm{CH}_{3} \mathrm{NH}_{3} \mathrm{PbI}_{3}$ lattice, which again trap photogenerated holes and then oxidize $\mathrm{I}^{-}$to $\mathrm{I}_{2}$. From the proposed overall reaction scheme, $\mathrm{Pb}^{0}$ and $\mathrm{PbI}_{2}$ are the final products of the photodecomposition. This is also the explanation why degradation in a vacuum/dark yields $\mathrm{PbI}_{2}$ as the final degradation product. This scheme is backed up by the in situ XRD results, where we only see peaks from $\mathrm{Pb}^{0}$ and $\mathrm{PbI}_{2}$ remaining after the photoinduced degradation in a vacuum. Additional support for the proposed reaction pathway comes from the evolution of the integrated intensity of the characteristic XRD peaks under vacuum/light. As shown in Fig. 5c, the formation of $\mathrm{Pb}^{0}$ and $\mathrm{PbI}_{2}$ has identical kinetics to the $\mathrm{CH}_{3} \mathrm{NH}_{3} \mathrm{PbI}_{3}$ decay. Therefore, on the basis of our in situ XRD results, we deduce that $\mathrm{CH}_{3} \mathrm{NH}_{3} \mathrm{PbI}_{3}$ is decomposed into $\mathrm{Pb}^{0}$ and $\mathrm{PbI}_{2}$ in the first 6 hours. After 6 hours, the photoinduced degradation ceases, because of the exhaustion of $\mathrm{CH}_{3} \mathrm{NH}_{3} \mathrm{I}$. A slight increase of the $\mathrm{Pb}^{0}$ intensity and a subtle attenuation of the $\mathrm{PbI}_{2}$ intensity are further derived from Fig. 5c. This is because $\mathrm{PbI}_{2}$ is slowly converted into $\mathrm{Pb}^{0}$ via the photolysis reaction mechanism. An in situ XRD study (Fig. S6†) was also conducted to track the kinetics of the photolysis of $\mathrm{PbI}_{2}$ under vacuum conditions. Fig. S6b $\uparrow$ shows the decomposition of $\mathrm{PbI}_{2}$ and the formation of
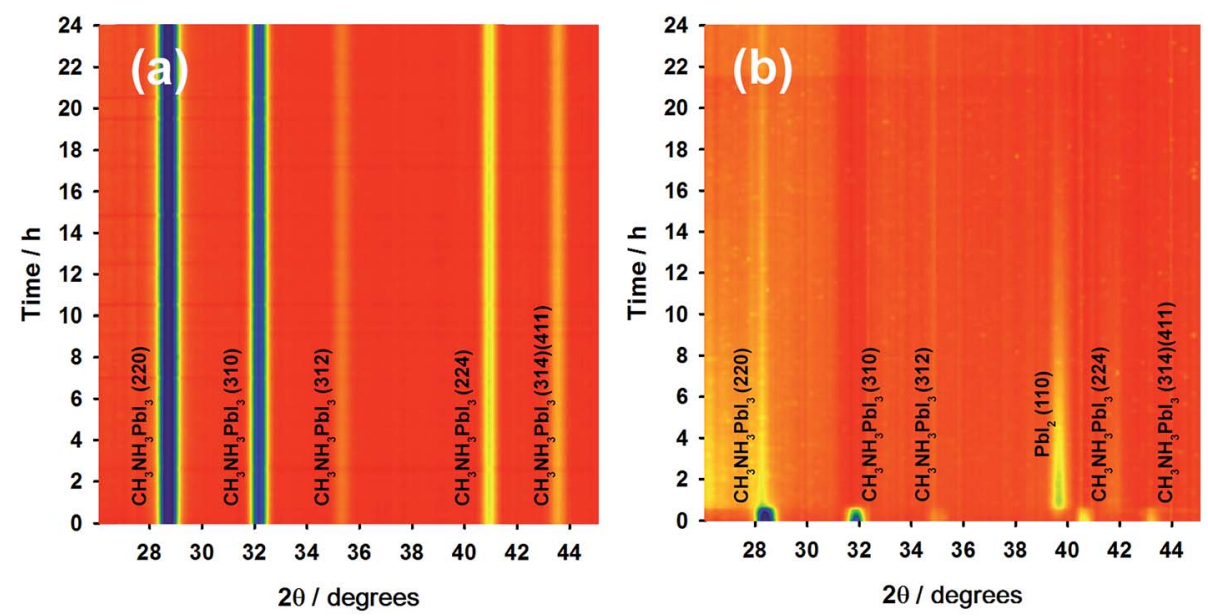

Fig. 6 In situ XRD spectra for $\mathrm{CH}_{3} \mathrm{NH}_{3} \mathrm{Pbl}_{3}$ films under air at $350 \mathrm{~K}$ without (a) or with (b) light illumination. 
$\mathrm{Pb}^{0}$ are at constant rates. This behavior is quite different from the two different photodecomposition kinetics of $\mathrm{CH}_{3} \mathrm{NH}_{3} \mathrm{PbI}_{3}$ (Fig. 5c). Therefore, the formation of $\mathrm{Pb}^{0}$ (Fig. 5c) is initially at a higher rate (e.g. in the first $6 \mathrm{~h}$ ) which is triggered by the removal of $\mathrm{CH}_{3} \mathrm{NH}_{3} \mathrm{I}$. The kinetics of the photolysis of pure $\mathrm{PbI}_{2}$ are much slower and with a constant rate (see Fig. S6†). Hence, the removal of $\mathrm{CH}_{3} \mathrm{NH}_{3} \mathrm{I}$ is the dominant mechanism in the photodegradation process of $\mathrm{CH}_{3} \mathrm{NH}_{3} \mathrm{PbI}_{3}$.

In the following, we further addressed the process and kinetics of photoinduced degradation of $\mathrm{CH}_{3} \mathrm{NH}_{3} \mathrm{PbI}_{3}$ in air by in situ XRD. As seen in Fig. 6a, aging in air/dark for 24 hours does not change the $\mathrm{CH}_{3} \mathrm{NH}_{3} \mathrm{PbI}_{3}$-related peaks. Under illumination, the $\mathrm{CH}_{3} \mathrm{NH}_{3} \mathrm{PbI}_{3}$ peaks decay extremely fast, and within less than 2 hours, all the peaks assigned to $\mathrm{CH}_{3} \mathrm{NH}_{3} \mathrm{PbI}_{3}$ disappeared. Because of the amorphous nature of the as-formed lead salts, no further signal was detected. Since all conditions, except light illumination, are the same between degradations in air/dark and air/light, the fast decomposition observed here is completely triggered by the light. Moreover, besides the fast decrease of $\mathrm{CH}_{3} \mathrm{NH}_{3} \mathrm{PbI}_{3}$-related peaks, lead iodide peaks $\left(2 \theta=39.5^{\circ}\right)$ also decrease but at a somewhat lower rate. As seen in Fig. 6b, the peak at $2 \theta=39.5^{\circ}$ reaches its maximum only after two hours and then attenuates until it totally vanishes. This attenuation is again attributed to the photolysis of $\mathrm{PbI}_{2}$. When the photolysis of $\mathrm{PbI}_{2}$ occurs in air, lead salts are found as products. ${ }^{32-35}$ This is in excellent agreement with our XPS results; see above.

We finally discuss the role of the components in air (nitrogen, oxygen and water) in the photoinduced degradation mechanism. In previous aging experiments under $\mathrm{N}_{2}$ /dark and $\mathrm{N}_{2}$ /light, $\mathrm{N}_{2}$ has been demonstrated to be inert to $\mathrm{CH}_{3} \mathrm{NH}_{3} \mathrm{PbI}_{3}$. Haque and co-workers showed that upon exposure of $\mathrm{CH}_{3} \mathrm{NH}_{3} \mathrm{PbI}_{3}$ films to dry air under light illumination, superoxide is generated by an electron transfer from $\mathrm{CH}_{3} \mathrm{NH}_{3} \mathrm{PbI}_{3}$ to $\mathrm{O}_{2}$. This superoxide attacks the $\mathrm{CH}_{3} \mathrm{NH}_{3} \mathrm{PbI}_{3}$ layer leading to the formation of methylamine $\left(\mathrm{CH}_{3} \mathrm{NH}_{2}\right), \mathrm{PbI}_{2}, \mathrm{I}_{2}$, and $\mathrm{H}_{2} \mathrm{O}$ as degradation products. ${ }^{36}$ Without water, lead salts cannot be formed, and this points out that moisture (water) is a requisite reactant for the reaction of photoinduced degradation of $\mathrm{CH}_{3} \mathrm{NH}_{3} \mathrm{PbI}_{3}$. For verifying the effect of oxygen, in the photoinduced degradation process, we choose a gas atmosphere of nitrogen which is saturated with water vapor. The resulting photoinduced degradation features only peaks of $\mathrm{PbI}_{2}$ and $\mathrm{CH}_{3} \mathrm{NH}_{3} \mathrm{PbI}_{3}$ in the X-ray diffraction (Fig. S7a $\dagger$ ). Furthermore, the degradation product was investigated by XPS. From the absence of a carbonate peak in the $\mathrm{C} 1 \mathrm{~s}$ spectrum (Fig. S7b $\dagger$ ) and any oxygen-related peak in the $\mathrm{O} 1$ s spectrum (Fig. S7c $\dagger$ ), we deduce that in this atmosphere, lead salts could not be formed. This behavior strongly suggests that oxygen is another essential factor for the photodecomposition of $\mathrm{CH}_{3} \mathrm{NH}_{3} \mathrm{PbI}_{3}$ into lead salts. According to the above results, it is clear that both oxygen and water contribute to the fast photoinduced degradation of $\mathrm{CH}_{3} \mathrm{NH}_{3} \mathrm{PbI}_{3}$ in air atmosphere.

\section{Conclusion}

In summary, we presented an in-depth ex situ and in situ study of the degradation of methylammonium lead triiodide $\left(\mathrm{CH}_{3} \mathrm{NH}_{3} \mathrm{PbI}_{3}\right)$ perovskite films in the dark and under light illumination under inert, vacuum and ambient (40\% rel. humidity) conditions. Different from the negligible changes under an inert $\mathrm{N}_{2}$ atmosphere, photoinduced degradation was directly observed under vacuum and in air. In situ XRD shows that, under vacuum and light, metallic lead $\left(\mathrm{Pb}^{0}\right)$ and lead iodide $\left(\mathrm{PbI}_{2}\right)$ are formed as the dominant degradation products within only 2 hours. Furthermore, the present findings suggest that photoinduced degradation in a vacuum starts with the creation of iodine vacancies via the volatilization of $\mathrm{CH}_{3} \mathrm{NH}_{3} \mathrm{I}$. In air, perovskite degrades into lead salts (e.g. $\mathrm{PbO}, \mathrm{Pb}(\mathrm{OH})_{2}$ and $\mathrm{PbCO}_{3}$ ), and we conclude that both oxygen and water cause the photoinduced decomposition. The observed results of photoinduced degradation are an important guidance to direct further research and development for more stable perovskite materials. Experiments incorporating high intensity light illumination (e.g. Raman, photoluminescence and laser beam induced current) should be performed with caution to exclude the interference from photoinduced degradation. Because photoinduced degradation in air is based on the combined effect from oxygen and water, encapsulation and the design of more hydrophobic surfaces may be beneficial to gain long-term stable perovskite devices. To further promote the application of perovskite solar cells for space applications, photoinduced degradation of $\mathrm{CH}_{3} \mathrm{NH}_{3} \mathrm{PbI}_{3}$ perovskite films under vacuum should also gain more attention.

\section{Acknowledgements}

This work was financially supported by the Cluster of Excellence "Engineering of Advanced Materials" (EAM). The authors would like to acknowledge the financial support from the DFG research training group GRK 1896 at Erlangen University and from the Joint Project Helmholtz-Institute Erlangen Nürnberg (HI-ERN) under project number DBF01253. C. J. B. gratefully acknowledges the financial support through the "Aufbruch Bayern" initiative of the state of Bavaria (EnCN and Solar Factory of the Future), the Bavarian Initiative "Solar Technologies go Hybrid" (SolTech) and the "Solar Factory of the Future" with the Energy Campus Nürnberg (EnCN). X. T., H. C. and S. C. would also like to acknowledge the financial support from the China Scholarship Council (CSC).

\section{Notes and references}

1 M. M. Lee, J. Teuscher, T. Miyasaka, T. N. Murakami and H. J. Snaith, Science, 2012, 338, 643-647.

2 M. Liu, M. B. Johnston and H. J. Snaith, Nature, 2013, 501, 395-398.

3 S. Yakunin, M. Sytnyk, D. Kriegner, S. Shrestha, M. Richter, G. J. Matt, H. Azimi, C. J. Brabec, J. Stangl, M. V. Kovalenko and W. Heiss, Nat. Photonics, 2015, 9, 444-449.

4 Z.-K. Tan, R. S. Moghaddam, M. L. Lai, P. Docampo, R. Higler, F. Deschler, M. Price, A. Sadhanala, L. M. Pazos, D. Credgington, F. Hanusch, T. Bein, H. J. Snaith and R. H. Friend, Nat. Nanotechnol., 2014, 9, 687-692. 
5 M. Saliba, S. M. Wood, J. B. Patel, P. K. Nayak, J. Huang, J. A. Alexander-Webber, B. Wenger, S. D. Stranks, M. T. Hörantner, J. T.-W. Wang, R. J. Nicholas, L. M. Herz, M. B. Johnston, S. M. Morris, H. J. Snaith and M. K. Riede, Adv. Mater., 2016, 28, 923-929.

6 T. Leijtens, G. E. Eperon, N. K. Noel, S. N. Habisreutinger, A. Petrozza and H. J. Snaith, Adv. Energy Mater., 2015, 5, 1500963.

7 Y. Rong, L. Liu, A. Mei, X. Li and H. Han, Adv. Energy Mater., 2015, 5, 1501066.

8 X. Li, M. Tschumi, H. Han, S. S. Babkair, R. A. Alzubaydi, A. A. Ansari, S. S. Habib, M. K. Nazeeruddin, S. M. Zakeeruddin and M. Grätzel, Energy Technol., 2015, 3, 551-555.

9 J. Yang, B. D. Siempelkamp, D. Liu and T. L. Kelly, ACS Nano, 2015, 9, 1955-1963.

10 B. Conings, J. Drijkoningen, N. Gauquelin, A. Babayigit, J. D'Haen, L. D'Olieslaeger, A. Ethirajan, J. Verbeeck, J. Manca, E. Mosconi, F. De Angelis and H. Boyen, Adv. Energy Mater., 2015, 5, 1500477.

11 Y. Yuan, Q. Wang, Y. Shao, H. Lu, T. Li, A. Gruverman and J. Huang, Adv. Energy Mater., 2016, 6, 1501803.

12 L. Meng, J. You, T.-F. Guo and Y. Yang, Acc. Chem. Res., 2016, 49, 155-165.

13 H. Chen, X. Pan, W. Liu, M. Cai, D. Kou, Z. Huo, X. Fang and S. Dai, Chem. Commun., 2013, 49, 7277-7279.

14 H. S. Jung and N.-G. Park, Small, 2015, 11, 10-25.

15 M. R. Hoffmann, S. T. Martin, W. Choi and D. W. Bahnemannt, Chem. Rev., 1995, 95, 69-96.

16 T. Leijtens, G. E. Eperon, S. Pathak, A. Abate, M. M. Lee and H. J. Snaith, Nat. Commun., 2013, 4, 2885.

17 K. Jeuris, L. Groenendaal, H. Verheyen, F. Louwet and F. C. De Schryver, Synth. Met., 2003, 132, 289-295.

18 U. B. Cappel, T. Daeneke and U. Bach, Nano Lett., 2012, 12, 4925-4931.

19 X. H. Zhu, B. J. Zhao, S. F. Zhu, Y. R. Jin, Z. Y. He, J. J. Zhang and Y. Huang, Cryst. Res. Technol., 2006, 41, 239-242.
20 A. Dualeh, N. Tétreault, T. Moehl, P. Gao, M. K. Nazeeruddin and M. Grätzel, Adv. Funct. Mater., 2014, 24, 3250-3258.

21 M. Volpe, D. Oliveri, G. Ferrara, M. Salvaggio, S. Piazza, S. Italiano and C. Sunseri, Hydrometallurgy, 2009, 96, 123131.

22 M. M. Rahman, K. M. Krishna, T. Soga, T. Jimbo and M. Umeno, J. Phys. Chem. Solids, 1999, 60, 201-210.

23 P. G. Yot and F. O. Méar, J. Hazard. Mater., 2009, 172, 117123.

24 W. Huang, J. S. Manser, P. V. Kamat and S. Ptasinska, Chem. Mater., 2016, 28, 303-311.

25 D. Payne, R. Egdell, D. Law, P. Glans, T. Learmonth, K. Smith, J. Guo, A. Walsh and G. Watson, J. Mater. Chem., 2007, 17, 267-277.

26 H. Wang, A. Zhou, F. Peng, H. Yu and J. Yang, J. Colloid Interface Sci., 2007, 316, 277-283.

27 K. S. Kim, T. J. O'Leary and N. Winograd, Anal. Chem., 1973, 45, 2214-2218.

28 D. Vantelon, A. Lanzirotti, A. C. Scheinost and R. Kretzschmar, Environ. Sci. Technol., 2005, 39, 4808-4815.

29 S. De Wolf, J. Holovsky, S.-J. Moon, P. Löper, B. Niesen, M. Ledinsky, F.-J. Haug, J.-H. Yum and C. Ballif, J. Phys. Chem. Lett., 2014, 5, 1035-1039.

30 J. Tauc, R. Grigorovici and A. Vancu, Phys. Status Solidi, 1966, 15, 627-637.

31 I. Deretzis, A. Alberti, G. Pellegrino, E. Smecca, F. Giannazzo, N. Sakai, T. Miyasaka and A. La Magna, Appl. Phys. Lett., 2015, 106, 131904.

32 J. Arends and J. F. Verwey, Phys. Status Solidi, 1967, 23, 137145.

33 M. R. Tubbs, Phys. Status Solidi, 1972, 11, 11-50.

34 M. G. Albrecht and M. Green, J. Phys. Chem. Solids, 1977, 38, 297-306.

35 S. D. R. Wilson and A. Hulme, Proc. R. Soc. A, 1983, 387, 133146.

36 N. Aristidou, I. Sanchez-Molina, T. Chotchuangchutchaval, M. Brown, L. Martinez, T. Rath and S. A. Haque, Angew. Chem., Int. Ed., 2015, 54, 8208-8212. 